\title{
A TUTELA DOS DIREITOS FUNDAMENTAIS DOS POVOS ISLÂMICOS NO SISTEMA REGIONAL ÁRABE DE PROTEÇÃO DOS DIREITOS HUMANOS
}

\author{
CUSTODY OF FUNDAMENTAL RIGHTS OF ISLAMIC PEOPLE IN THE ARAB \\ REGIONAL PROTECTION SYSTEM OF HUMAN RIGHTS
}

${ }^{1}$ Adriana Ferreira Serafim de Oliveira

\section{RESUMO}

O presente artigo objetiva discutir a tutela dos direitos fundamentais dos povos islâmicos no sistema regional árabe de proteção dos direitos humanos, tendo em vista os tratados internacionais de direitos humanos na concepção islâmica, a saber, a Carta Árabe dos Direitos Humanos e a Declaração do Cairo dos Direitos Humanos. A metodologia utilizada neste artigo refere-se à pesquisa e posterior análise de abordagem qualitativa em bibliografias nos campos de estudo do Direito, da Sociologia e da História em relação aos povos árabes e islâmicos, quanto sua concepção de Estado, sociedade, cultura e consequentemente, o direito.

Palavras-chave: Direitos humanos, Sistema regional árabe de proteção dos direitos humanos, Carta árabe dos direitos humanos, Declaração do cairo dos direitos humanos, Direito islâmico

\begin{abstract}
The present article aims to discuss the custody of the fundamental rights of the Islamic people at Arab regional protection system of human rights, in view of the international treaties on human rights in the Islamic conception, namely the Arab Charter on Human Rights and the Cairo Declaration on Human Rights. The methodology used in this article was the research and after analysis in the qualitative way in bibliographies in the fields of studies of Law, of Sociology and History in relation to the Arab and Islamic people, as their conception of the State, society, culture and therefore, the law.
\end{abstract}

Keywords: Human rights, Arab regional protection system of human rights, Arab charter on human rights, Cairo declaration on human rights, Islamic law

\footnotetext{
${ }^{1}$ Doutoranda em Educação pela Universidade Estadual Paulista Júlio de Mesquita Filho - UNESP, São Paulo (Brasil). Professora de Direito pela Universidade Metodista de Piracicaba - UNIMEP, São Paulo (Brasil).

E-mail: adrianaferserol@ hotmail.com
} 


\section{Introdução}

O presente estudo objetiva investigar a eficácia da tutela dos direitos fundamentais dos povos islâmicos de acordo com seus tratados internacionais aplicados ao sistema regional árabe de proteção dos direitos humanos.

A metodologia utilizada para a elaboração deste artigo engloba a pesquisa interdisciplinar e posterior análise de abordagem qualitativa em bibliografias nos campos de estudo e pesquisa do Direito, da Sociologia e da História envolvendo a cultura, mais especificamente a religião dos povos islâmicos.

A escolha pela abordagem qualitativa permite a identificação dos significados culturais presentes nos diferentes grupos de participantes. Essa abordagem trabalha com valores, crenças, hábitos, atitudes, representações, opiniões e adequa-se a aprofundar a complexidade de fatos e processos particulares e específicos tanto para indivíduos como para grupos. (PAULILO, 1999, p.135; 136).

Desse modo, a metodologia é apropriada para o estudo em questão, o qual envolve culturas e sua compreensão sobre direitos humanos.

O estudo da tutela dos direitos fundamentais destinados aos povos islâmicos, descritos nos tratados internacionais islâmicos de direitos humanos e a concepção dos direitos humanos pela Liga dos Estados Árabes, faz-se necessário pela atualidade e frequência com que o islamismo é citado e discutido pelas mídias faladas e escritas, disseminando informações negativas e provocando terror na sociedade internacional.

Conforme a linha cronológica histórica entende-se que o pensamento científico para os povos ocidentais tomou novos contornos a partir da Idade Moderna, a qual se desenrolou entre os séculos XV-XVIII. Importante salientar que houve a separação entre os poderes do Estado e o poder espiritual, os quais estavam centrados na pessoa do governante.

Um dos fatos geradores da transição do pensamento científico para o campo racional e não mais religioso assenta-se na separação dos poderes estatal e espiritual, os quais estavam centrados nas pessoas dos governantes. A partir de então o princípio da laicidade ${ }^{1}$ têm sido um dos pilares de construção e fundamentação das legislações que regem os governos ocidentais, o qual determina que a razão do Estado esteja acima dos interesses privados de qualquer forma.

\footnotetext{
${ }^{1}$ A laicidade é um princípio norteador das normas jurídicas, requisito primordial, essencial e indispensável para a constituição da democracia. (OLIVEIRA, 2014, p. 93).
} 
Os doutos das secções da fé islâmica reflexionam cientificamente sobre a hermenêutica de suas legislações, entretanto, com mais ou menos flexibilidade de interpretação, deitam suas bases no livro sagrado ou na palavra e vida do profeta Maomé, tendo em vista que o poder de Estado está estritamente conectado ao poder espiritual.

Dessa forma, podemos iniciar um entendimento quanto às causas das sociedades ocidentais e ou ocidentalizadas serem resistentes na compreensão das razões que movem um Estado teocrático, perfazendo críticas fundamentadas à ineficácia do Estado islâmico em tutelar os direitos humanos aos seus cidadãos.

Em contrapartida, as sociedades muçulmanas disparam que o modelo ocidental de Estado demonstra que não cumpre totalmente a função de proteger os direitos humanos de seus nacionais, pois foi necessária a instalação dos sistemas de proteção regionais e internacional dos direitos humanos.

No tocante ao direito internacional dos direitos humanos, a compatibilidade dos tratados internacionais islâmicos de direitos humanos em relação ao sistema regional árabe de proteção dos direitos humanos é questionável quanto sua tutela aos povos islâmicos que habitam as regiões dos países que fazem parte da Liga Árabe e dos países localizados no continente africano seguidores da fé muçulmana.

Um fator relevante nesta questão são as sociedades coexistentes no planeta. Os povos são multiculturais e mesmo dentro de uma comunidade regional há diferenças culturais, o que dificulta a instituição de uma legislação internacional que tutele todos os seres humanos igualmente, prevalecendo em cada Estado sua legislação doméstica e diferenciada à medida que os valores afastam-se dos cunhados pelos povos ocidentalizados.

Desse modo, os tratados internacionais islâmicos, a saber, a Carta Árabe dos Direitos Humanos e a Declaração do Cairo dos Direitos Humanos, em tese, no corpo dos documentos internacionais, tutelam os direitos fundamentais dos cidadãos aos quais se destinam, entretanto, a compatibilidade com o sistema regional árabe de proteção dos direitos humanos merece considerações tendo em vista que referidos documentos internacionais retornam aos livros sagrados muçulmanos para dirimirem seus questionamentos.

\section{Os Estados islâmicos, sua cultura e religião}

O islamismo, também chamado de fé muçulmana ou maometana, é a terceira religião monoteísta revelada a um profeta. A primeira, o judaísmo e a segunda, o cristianismo e todas têm números consideráveis de fiéis. As sociedades ocidentais foram movidas pelas religiões 
quando o poder estatal estava conectado ao poder espiritual e ainda o são pela disseminação de seus costumes e tradições.

$\mathrm{Na}$ atualidade, as sociedades islâmicas são movidas por sua religião e esta especificidade não é entendida pelos ocidentais na medida em que nos consideramos todos iguais perante os direitos humanos, entretanto, com valores diversos e anseios diferentes.

$\mathrm{O}$ bem e o mal enraizados nas diretrizes das comunidades formadoras dos Estados componentes da sociedade internacional, explica-se através de Nietzsche (2013), o qual considera que o problema teológico da fé e da ciência, também é o problema do instinto e da razão, pois gera um conflito no ser humano ao ser chamado a avaliar as coisas; se o instinto merece mais autoridade que a razão, a qual aprecia segundo os motivos que age, ou seja, em conformidade com um fim utilitário. (NIETZSCHE, 2013, p. 121).

Para compreender o cerne das sociedades islâmicas, é necessário entender o que é Islã ou islamismo. Islã significa submissão a Allah, Deus em árabe. O anjo que ditou sua mensagem em língua árabe ao profeta Maomé, chama-se Gabriel, como o anjo anunciado pelo judaísmo e pelo cristianismo. A mensagem que constituiu o livro sagrado muçulmano denominado Alcorão, que significa "recitação" em árabe trata-se de um código moral, social, cultural, religioso e jurídico seguido pelos fiéis da fé islâmica.

Segundo Balta (1986) a compreensão do Islã tem múltiplas dimensões, remontando à Arábia desértica de organização tribal, com os beduínos nômades e de adoração aos deuses politeístas. (BALTA, 1986, p. 144; 145).

Balta (1986) tece considerações ao Islã de acordo com a cultura dos povos de cada tribo convertida e incorporada à fé islâmica, quanto à organização do Estado e consequentemente com a interpretação da atualidade para elaboração das leis.

O profeta muçulmano viveu no período de 570-632 da era cristã e tinha como profissão o comércio. Durante o mês conhecido como Ramadã ${ }^{2}$, no ano de 610 , viveu a experiência, conhecida como a recitação pelo anjo Gabriel do livro sagrado denominado Alcorão. Demant (2011) relata que a Arábia pré-islâmica era composta por árabes pagãos e politeístas, entretanto, eram conhecedores de um Deus também, Allah. (DEMANT, 2011, p. $23 ; 24)$.

O islamismo superou os diferentes costumes tribais e unificou a sociedade arábica, a qual se guia pelo patriarcalismo, com a pregação da justiça social entre os membros das comunidades, mesmo que as mulheres não sejam reconhecidas no mesmo peso e medida que

\footnotetext{
${ }^{2}$ Nono mês do calendário muçulmano onde se observa o jejum para lembrar a revelação de Allah através do anjo ao profeta Maomé. (ARBEX, 1997, p. 102).
} 
os homens. A genealogia do poder político no Islã encontra-se em toda a trajetória profética de Maomé, sendo a autoridade do profeta reconhecida sem limite pelos seus seguidores, entretanto, o profeta recordava continuamente seus seguidores que era apenas um enviado. (Idem, p. 24; 25).

Segundo Hourani (2011), os poderes do Estado (político, militar e administrativo) não eram um desvio da espiritualidade, mas a própria essência da religião, pois o bem estar político da comunidade muçulmana era uma questão suprema, de justiça social. (HOURANI, 2011, p. 33).

Como parte dessa justiça social, as instituições do Estado deveriam atingir o ideal corânico de igualdade entre todos os seguidores islâmicos e aos seus líderes políticos era vetada a crueldade e a exploração, práticas reiteradas nos conflitos entre as tribos da Arábia préislâmica.

Os muçulmanos experimentam uma cultura diferente dos ocidentais, observando-se que no interior do Islamismo existem várias secções, embora haja comunidades islâmicas espalhadas pelo mundo, o que em certas circunstâncias envolve os islâmicos em conflitos de identidade, também por suas sociedades orientarem-se pelo poder patriarcal onde a mulher sempre é descrita em relação ao homem.

O Islã divide-se em secções de acordo com as interpretações do livro sagrado. As duas maiores divisões são os sunitas e os xiitas. Os sunitas consideram que o líder da comunidade islâmica deve ser aquele que tenha melhores capacidades políticas e religiosas para assumir a função e interpretam o Alcorão à luz da modernidade.

Os xiitas acreditam que após a morte de Maomé, seu primo e genro, Ali ibn Abu Talib, é o seu legítimo sucessor e o líder tem que ser nomeado pelo seu antecessor, ascendente do profeta Maomé, dos quais os sucessores legais são os imãs.

Dentro da secção xiita, pela tensão imposta na não interpretação dos versos do Alcorão é que derivam os fundamentalistas e entre estes, os considerados pelos ocidentais, radicais quanto a não interpretação do disposto no livro sagrado em relação à modernidade, os terroristas. (SILVA, 2011, p. 4; 28).

Portando, o islamismo comporta várias designações de islâmicos ou muçulmanos, também conhecidos por maometanos, os quais nem sempre estão de acordo entre suas comunidades quanto ao entendimento e interpretação dos versos do Alcorão e da palavra e vida do profeta Maomé, qual seja, a Sharia. 


\section{Entendimentos conflitantes sobre direitos humanos nas sociedades ocidentais e nas islâmicas}

A concepção do que são direitos humanos não alcança a igualdade entre os povos, pois as sociedades e comunidades componentes da sociedade internacional possuem valores diversos quanto à vida dos seres humanos e sua trajetória do nascimento à morte.

Herrera Flores (2009) defende que os direitos humanos são produtos culturais, e conforme observamos nas sociedades islâmicas, estas possuem anseios diferentes das sociedades ocidentais, pois suas construções se dão sobre valores diversos.

Seguindo a linha acadêmica de Herrera Flores, os direitos humanos são construídos e não naturais, pois há uma falsa ideia vigente no mundo em geral, inclusive o acadêmico, de que os seres humanos nascem em qualquer lugar do globo terrestre com os direitos humanos prontos, o que não corresponde à verdade, pois são construídos de acordo com as necessidades de uma sociedade. (HERRERA FLORES, 2009, p. 2; 100).

Assim, os produtos culturais são diferentes entre si, podendo ser parecidos, tocaremse em alguns pontos, mas a sociedade internacional é divergente em suas necessidades até pelas limitações naturais e básicas, tais como clima, relevo, disponibilidade de água potável e possibilidades de produção de alimentos. Os direitos humanos não são abstratos e nem ideológico, mas sim processos de lutas pela igualdade, e isso os tornam provisórios em relação a essas lutas e seus efeitos, efêmeros na limitação da equação entre tempo/espaço. (Idem, p. 39; 112).

Na literatura jurídica brasileira, Barroso (2009) corrobora com Herrera Flores (2009) quando discorre que: "o direito é uma invenção humana, um fenômeno histórico e cultural, concebido como técnica de solução de conflitos e instrumento de pacificação social". (BARROSO, 2009, p. 13).

Com as considerações desses autores, observa-se que as normas jurídicas do direito doméstico das nações ao conflitarem, não estão em oposição entre si por força de uma soberania, mas primeiro em conformidade com o que suas sociedades nacionais requereram.

Segundo Donelly (2007), o relativismo cultural tem sido provavelmente a questão mais discutida na teoria dos direitos humanos, a esse respeito o autor defende uma forma de universalismo que também permite espaço para importantes reivindicações de relativismo, o que se pode chamar de "universalidade relativa" dos direitos humanos. No entendimento do mesmo autor, a universalidade antropológica e a ontológica são empiricamente, filosoficamente ou politicamente indefensáveis. (DONELLY, 2007, p. 281; 282). 
Os direitos humanos no sentido literal do termo são normalmente entendidos como sendo os direitos que se tem simplesmente porque se é humano. Os direitos humanos são também direitos inalienáveis, porque ser ou não humano é um fato inalterável da natureza, e não algo que seja adquirido ou pode ser perdido. (Idem, p. 283).

No mesmo sentido, Herrera Flores (2009) considera ainda que nenhuma norma jurídica é total, porque a totalidade é falsa tendo em vista sempre existir a possibilidade de um limite e de mudanças que tornem essa norma ineficaz para uma determinada sociedade dentro de um contexto histórico. (HERRERA FLORES, 2009, p. 160; 161).

Comparando os sistemas jurídicos, ocidental e islâmico, a lei maior de um Estado islâmico está assentada no que dispõem o Alcorão e a Sharia ${ }^{3}$ e toda a legislação desses países remetem aos livros sagrados citados. Segundo Arnaldez (1991), especialistas sobre os princípios da lei corânica islamizam o Estado de Direito emprestado de sistemas não muçulmanos, tais como os sistemas: bizantino, o de direito romano, o persa ou o rabínico. É este processo de islamização que permite aos muçulmanos a reconstrução do passado e o crescimento atual dentro dos seus padrões, primando pela justiça social. (ARNALDEZ, 1991, p.83; 88).

Exemplificando, as mulheres nas comunidades muçulmanas transitam socialmente de acordo com a tensão maior ou menor dos valores morais da sociedade que por natureza construiu-se norteada pelos ideais patriarcais, onde o homem é o provedor maior da família e quem dita regras do que as mulheres sob sua guarda podem ou não fazer. (OLIVEIRA, 2014, p. 72).

Dessas considerações, abstrai-se que a positivação de diferentes e diversos direitos humanos de acordo com a identidade cultural dos povos não garante que toda a população mundial seja alcançada em seus anseios por um longo período pela natureza mutável dos direitos com o passar do tempo.

\section{Os direitos humanos e os sistemas regionais de proteção dos direitos humanos da Liga} Árabe dos Estados e do continente africano

Na metade do século XX, com as consequências desastrosas aos seres humanos das guerras mundiais, o clamor à proteção dos direitos humanos e positivação de normas para tutelar os direitos fundamentais ganhou espaço e força.

\footnotetext{
${ }^{3}$ Sharia trata da palavra e da vida do profeta Maomé. (OLIVEIRA, 2014, 22; 25).
} 
A proteção dos direitos individuais efetuava-se no contexto das relações interestatais, ou seja, entre os atores internacionais até a criação dos sistemas internacionais e regionais de proteção dos direitos humanos. (TRINDADE, 1997, p.31; 32).

\subsection{Considerações sobre a concepção de direitos humanos e os sistemas de proteção desses direitos}

Ao ser reconhecida a desigualdade entre direitos, na outra ponta da mesma via estão as vontades para erradicá-la. A vulnerabilidade é superável, se as ferramentas necessárias são desenvolvidas para quem clama pela tutela dos seus direitos. O grau de vulnerabilidade das pessoas dependente de diferentes fatores físicos, econômicos, sociais e políticos, mas pode-se implementar medidas para mitigar o efeito desses fatores, ou seja, podem ser colocados meios para reduzir os efeitos do risco de lesões dos direitos. Entre esses meios está o desenvolvimento de alerta para lesões, a preparação para elas, a capacidade de se recuperar dessas violações e a resistência contra elas. (BELTRÃO; BRITO FILHO; GÓMEZ, et al, 2015, p. 8; 9).

Desse modo, as primeiras tentativas de se positivar a responsabilidade internacional dos Estados são do início do século XX, entretanto, demorou um século para a aprovação, em 2001, na Organização das Nações Unidas (ONU) de um projeto com 58 artigos aplicável à significativa parte da sociedade internacional, no qual são especificados os níveis de responsabilidade dos Estados, as espécies de reparação e a implementação das decisões. (COELHO, 2008, p. 42; 43).

A respeito ao clamor por positivação de normas que tutelem os direitos humanos, Blanes Sala (2011) considera:

\footnotetext{
Há um vínculo estreito entre o corpo jurídico que conforma o conjunto do que se conhece como 'direitos humanos' e o panorama das relações internacionais. [...] a aplicação eficaz no seio dos Estados do conjunto dos direitos fundamentais, [...] só será possível após a Declaração Universal dos Direitos Humanos em 1948, impulsionada pela Organização das Nações Unidas. Quando, então, se criam mecanismos de proteção internacional, seja mediante a ratificação de tratados, seja mediante a instalação de tribunais de caráter supraestatal. (BLANES SALA, 2011, p. 5).
}

Conforme Blanes Sala (2011), o chamamento das sociedades ocidentais pela criação de normas internacionais de garantia dos direitos fundamentais de seus cidadãos tem como um dos mais importantes e citados na ordem mundial e legislações domésticas, a Declaração 
Universal dos Direitos do Homem de 1948 e consequentemente advieram os sistemas de proteção dos direitos humanos.

$\mathrm{O}$ instituto da responsabilidade garante a ordem jurídica entre os Estados. O entendimento internacional é que os Estados têm responsabilidade objetiva, independente de culpa estatal, exigindo-se uma conduta comissiva ou omissiva do Estado, configurando violação de obrigação internacional, comprovando o nexo de causalidade. (Idem, p. 43).

A capacidade processual dos indivíduos e grupos sociais, como atores e sujeitos de direito no cenário internacional, reconhecida pelos tribunais internacionais na atualidade era objeto de preocupação dos internacionalistas há mais de meio século e as experiências e lições das guerras mundiais contribuíram decisivamente para a preocupação e ação dos internacionalistas.

No cenário internacional, o sistema de proteção dos direitos humanos desenvolveu-se consideravelmente nas últimas décadas, entretanto, lentamente e ineficientemente, tendo em vista que as situações de discriminação persistem no mundo, demonstrando que ainda os sistemas de proteção dos direitos humanos revelam-se insuficientes para dar uma resposta adequada à natureza específica dos problemas e necessidades de um grupo vulnerável. (LUGO, 2015, p. 159).

Os sistemas de proteção dos direitos humanos podem ser acionados quando há violação dos direitos humanos por parte de um Estado signatário. O ofendido por meio de uma organização não governamental ou de um procurador peticiona ao sistema respectivo reclamando da violação sofrida. A petição é submetida a um juízo de admissibilidade e segue ou não para julgamento, observando-se que as cortes e comissões desses sistemas guardam suas particularidades quanto aos trâmites internos da petição. O Estado violador é informado dessa acusação, podendo ser julgado culpado ou inocente. Se o Estado for julgado culpado, a sentença poderá conter o dever de reparação, inclusive pecuniária. (PIOVESAN, 2011, p. 84; 89).

Para o estudo da compatibilidade dos tratados internacionais islâmicos sobre direitos humanos aos povos pertencentes à Liga dos Estados Árabes, atentamos para o sistema regional árabe de proteção dos direitos humanos e para a diferenciação do sistema regional africano de proteção dos direitos humanos por estar instalado no continente africano, o qual possui grande número de comunidades seguidoras da fé islâmica.

No mesmo sentido, cabe esclarecer que a Europa conta com o sistema regional europeu de proteção dos direitos humanos e nas Américas está instalado o sistema regional interamericano de proteção dos direitos humanos. 


\subsection{Sistema regional árabe de proteção dos direitos humanos}

Quanto ao sistema regional árabe de proteção dos direitos humanos, a Carta Árabe dos Direitos Humanos (1994) é o tratado internacional fundador, documento de que são signatários os países membros da Liga Árabe ${ }^{4}$. Esse sistema está em fase de estruturação, contudo, conta com o trabalho da Comissão Árabe Permanente de Direitos Humanos, a qual se baseia na Carta Árabe dos Direitos Humanos. (COELHO, 2008, p. 50) e (OLIVEIRA, 2014, p. 50; 52).

O primeiro projeto da Liga Árabe foi de 12 de setembro de 1966, restando uma resolução. Em 15 de setembro de 1994, o Conselho da Liga Árabe elaborou uma conferência sobre o tema dos direitos humanos em Beirute e como resultado adotou-se uma Carta de Direitos Humanos, a qual foi compilada a partir de textos diversos. Essa Carta não entrou em vigor, mas com sua revisão possibilitou que em 15 de maio de 2008 finalmente esse tratado internacional entrasse em vigor dando início ao sistema regional árabe de proteção de direitos humanos. (FEFERBAUM, 2012, p.61; 62).

A mesma autora considera que esse documento internacional submete à interpretação de seus dispositivos à lei da Sharia, contradizendo o discurso universalista inserto em seu texto, deixando brechas para violações dos direitos humanos, especialmente em relação às minorias. (Idem, p. 63).

O texto da Carta Árabe dos Direitos Humanos é composto por um preâmbulo e 53 artigos, onde em suas principais tutelas, reconhece os direitos individuais e as liberdades civis, proclamando uma série de direitos dos povos, tais como, a autodeterminação, a obtenção e manutenção de suas riquezas e recursos naturais, o estabelecimento de seu estatuto político e do direito de assegurar o seu desenvolvimento econômico, social e cultural, entretanto, no artigo 25 da Declaração do Cairo dos Direitos Humanos, documento emitido para orientação geral dos Estados membros da Liga dos Estados Árabes, a Sharia islâmica é considerada a única fonte de referência para a explicação ou esclarecimento.

Conforme entendimento da Organização de Cooperação Islâmica, a Declaração do Cairo dos Direitos Humanos necessita de revisão e a maior crítica para o avanço do

\footnotetext{
${ }^{4} \mathrm{O}$ sistema árabe de proteção dos direitos humanos teve sua carta ratificada por países da Liga Árabe, tanto do continente africano como asiático. Marrocos, país do norte da África, juntamente com 07 países já membros do sistema africano de proteção dos direitos humanos, a saber - Tunísia, Egito, Sudão, Líbia, Síria, Argélia e Arábia Saudita - fazem parte do sistema árabe. (OLIVEIRA, 2014, p. 50).
} 
entendimento dos direitos humanos islâmicos, refere-se ao retorno à Sharia de suas disposições conforme o artigo $25^{5}$ deste documento internacional. (KAYAOGLU, 2013).

A Comissão Árabe Permanente de Direitos Humanos é o principal órgão político encarregado da proteção dos direitos humanos dentro do sistema da Liga Árabe. Reúne-se duas vezes por ano, ao nível dos Estados-Membros, e provou ser ineficaz, pois está centrada nas discussões sobre a liquidação do conflito árabe-israelense. A Comissão Permanente não tem o mesmo empenho em outras questões, apesar de um aumento no número de Conselhos de Ministros desde que levantes populares começaram na região. A Comissão tem um histórico do não exame de forma eficaz dos direitos humanos e de não se envolver nessas questões. Com efeito, pela sua própria natureza, carece de neutralidade suficiente para questionar lesões ou violações aos direitos humanos dentro dos Estados membros. (THE ARAB LEAGUE AND HUMAN RIGHTS, 2013, p. 5).

Os direitos reconhecidos em ambos tratados internacionais islâmicos demonstram um progresso na proteção dos direitos humanos, todavia seus textos apresentam limitações, especialmente a ausência de referência às garantias individuais. Esses documentos reconhecem a igualdade entre homens e mulheres perante a lei, mas os desigualam conforme se reportam como fonte suprema da lei islâmica ao Alcorão e à Sharia, não vetando expressamente a aplicação de penas cruéis, desumanas ou degradantes.

Demais projetos de tratados internacionais foram preparados por organizações não governamentais, especialmente os provenientes da União de Juristas Árabes em 1979 e do Instituto Internacional de Estudos Superiores em Ciências Criminais, o qual adotou em 1985 a Carta Árabe dos Direitos Humanos e das Pessoas no Mundo Árabe. Demais conferências foram organizadas por Organizações Não Governamentais (ONGs) sobre a questão dos direitos humanos regionais em 1987 e 1989, respectivamente no Sudão, e na Tunísia.

As Cartas e Declarações foram também adotadas por conferências diplomáticas, ONGs e pelos Estados, referindo-se aos dois projetos que o Conselho Islâmico da Europa aprovou, respectivamente, em Londres em abril de 1980 e em Paris em setembro de 1981, chamados a Declaração Islâmica Universal dos Direitos Humanos, projeto adotado pela organização da Conferência Islâmica sobre Direitos Humanos no Islã, e a Grande Carta Verde dos Direitos Humanos, adotada pela Assembleia Popular da Líbia em 1988. (ACHOUR, 1992, p.229; 231).

\footnotetext{
${ }^{5}$ Artigo 25: A Sharia islâmica é a única fonte de referência para a explicação ou esclarecimento de qualquer um dos artigos da presente nesta Declaração. (CAIRO DECLARATION ON HUMAN RIGHTS).
} 
A não separação dos poderes do Estado e religioso nos Estados onde o islamismo é a religião oficial, reportam seus tratados internacionais e sua legislação às convenções da fé e não à razão do Estado, pois neste caso a razão do Estado é o poder temporal. Os próprios tratados internacionais islâmicos em estudo são discordantes em seu texto, pois reconhecem direitos aos seres humanos e logo adiante em outro artigo os restringe ou proíbe sob alegações insuficientemente fundamentadas e ou esclarecidas.

\subsection{Sistema regional africano de proteção dos direitos humanos}

Quanto ao sistema regional africano de proteção dos direitos humanos, a África é formada por 54 países, entretanto, inicialmente com exceção do Marrocos, todos os demais países africanos ratificaram o tratado internacional que constituiu o sistema regional africano de proteção dos direitos humanos, a Carta Africana sobre os Direitos Humanos e dos Povos. (1981/1986).

O sistema regional africano de proteção dos direitos humanos foi criado na extinta Organização para a Unidade Africana (OUA), atual União Africana (UA). Tinha inicialmente apenas uma comissão, mas a decisão de complementar a Comissão com uma Corte Africana de Direitos Humanos foi tomada por meio do Protocolo em 1998 e a União Africana (UA) foi instituída em julho de 2002 (53 membros).

Esse sistema regional de proteção foi fundado pela Carta Africana sobre os Direitos Humanos e dos Povos (1981/86), a qual obteve 53 ratificações e o Protocolo à Carta (1998/2004) obteve 21 ratificações, entrando em vigor em janeiro de 2004. A cúpula da UA tomou uma decisão em julho de 2004 de fundir a Corte Africana ou Tribunal Africano de Direitos Humanos com a Corte Africana de Justiça.

Outros documentos internacionais foram assinados com relação aos direitos humanos no continente africano, a saber, a Convenção da UA que rege os aspectos específicos dos problemas dos refugiados na África (1969/1974) que obteve 45 ratificações, a Carta Africana sobre os Direitos e o Bem Estar da Criança (1990/1999) com 37 ratificações, o Protocolo à Carta Africana dos Direitos Humanos e dos Povos, a Carta sobre os Direitos das Mulheres na África (2003/2005) com 13 ratificações, sendo que ao menos 15 são exigidas. A Comissão foi estabelecida em 1987 e a sede está em Banjul na Gâmbia. (COELHO, 2008, p. 50).

O tratado internacional constitutivo do sistema regional africano de proteção dos direitos humanos, devido ao nacionalismo exagerado das ditaduras que perduravam durante a criação do texto da Carta Africana e que nasceram após a independência desses países, agora 
soberanos, criou apenas a comissão e não a corte desse sistema. A Corte, ou como descrito pelo acordo constitutivo, Tribunal dos Direitos do Homem e dos Povos, foi criada em 1998, por meio do Protocolo à Carta Africana de Direitos Humanos e dos Povos, cujo texto entrou em vigor no ano de 2004. (MATTHES, 2015, p. 9; 15).

Os cidadãos dos países da Liga dos Estados Árabes se sofrerem violações quanto aos direitos humanos por parte de seus Estados, internacionalmente, não possuem um sistema de proteção em funcionamento para apelarem, pois a constituição do sistema regional árabe de proteção dos direitos humanos está em andamento e os países da Liga que estão localizados no continente africano não são signatários da Carta Africana sobre os Direitos e Bem Estar dos Povos, portanto, não beneficiários das possíveis cautelas do sistema regional africano de proteção dos direitos humanos.

\section{Considerações finais}

O Islamismo é uma unidade em que pese não serem uniformes as culturas islâmicas nos países, nas sociedades e nas comunidades maometanas, independentemente da nação em que estão fixados os seguidores dessa fé, sejam Estados onde a religião islâmica é a oficial ou nações democráticas ao redor do globo.

Existem conflitos de interpretação do Alcorão e da Sharia entre as secções islâmicas, tendo em vista a expansão geográfica do islamismo durante a vida do profeta e posteriormente à morte, nas dominações de territórios e nações, pois culturas tribais e diferentes mesclaramse à fé adotada, carregando para o seio das sociedades islâmicas seus costumes.

Os islâmicos modernos reflexionam e discutem sobre as revelações do Alcorão e emitem suas opiniões em jurisprudências para serem seguidas em casos concretos, mas os conservadores não admitem essa prática e as questões que surgem no seio de suas sociedades são solucionadas sem o uso da hermenêutica.

No paralelo entre as sociedades islâmicas e ocidentais as diferenças culturais e de valores destacam-se e referendam a impossibilidade de considerar os direitos humanos universais, pois os direitos humanos muçulmanos e ocidentais são incompatíveis quanto à aplicabilidade de suas normas, tendo em vista que os Estados ocidentais orientam-se pelo princípio da laicidade e os países islâmicos têm como razão do Estado o código religioso, onde também assentam a moral e a ética que baseiam suas leis.

Nesse estudo foram considerados dois produtos culturais importantes das sociedades islâmicas destinados aos povos islâmicos, os tratados internacionais islâmicos, a saber, a 
Carta Árabe dos Direitos Humanos e a Declaração do Cairo dos Direitos Humanos, os quais são divergentes entre si por declararem universalidade para suas comunidades e serem excludentes às minorias em seu seio e dos tratados internacionais de direitos humanos ocidentais, exemplificando, da Declaração Universal dos Direitos Humanos (1948).

Essas contradições se dão porque os tratados internacionais islâmicos ao tutelarem os direitos humanos, consideram as leis corânicas e a palavra do profeta como a base da legislação islâmica, o que causa polêmica entre as secções islâmicas e, sobretudo, em relação aos direitos humanos construídos no Ocidente.

A concepção diferenciada dos direitos fundamentais nos países muçulmanos afirmada nos instrumentos de direitos humanos específicos para o mundo muçulmano trata-se de uma concepção particularista manifestada por ambiguidades nas constituições dos países da Liga dos Estados Árabes e na flexibilidade dos costumes conforme os tempos atuais, pois a universalidade que proclamam não é aproveitada por suas próprias comunidades quanto aos direitos fundamentais das minorias, incluindo às mulheres muçulmanas.

Os direitos humanos na concepção islâmica não são concebidos como inerentes à natureza do homem racional e livre, capaz de conhecer os seus direitos, mas sim como dons da vontade soberana de Allah, concedidos ao homem. Já o pensamento ocidental, ao ser reduzido ao racionalismo positivista, reforça a sua incompreensão com o pensamento das sociedades muçulmanas.

Os valores são diferentes no âmago das sociedades. É inerente da vida humana não respeitar o que não se conhece, entende ou acredita, então é preciso encontrar um mínimo denominador comum em matéria de direitos fundamentais, um ponto de equilíbrio dentro da sociedade internacional, buscando o entendimento multicultural da dignidade humana, preservando-se a individualidade de cada sociedade.

A política e o esforço para a manutenção do poder no status quo fomentam aos muçulmanos a cultura do medo da democracia vigente nas sociedades ocidentais, facilitando que as sociedades islâmicas rotulem o Ocidente como desconhecido e perigoso, passível de perverter tradições e costumes pela vivência do capitalismo e individualismo. De maneira similar, o Islã representa para os ocidentais mais terrorismo que religião. O princípio da laicidade aplicado ao caso concreto possibilitaria a não invocação da religião para encobrir interesses geopolíticos e econômicos.

Os sistemas regionais de proteção dos direitos humanos constituídos pela Liga dos Estados Árabes e pela União Africana não tutelam os direitos fundamentais com referência aos povos seguidores da fé islâmica que habitam as regiões geográficas desses países, os quais 
podem ser Estados violadores dos direitos humanos de seus nacionais e estrangeiros, tendo em vista a diversidade cultural e o exercício de poder dos governantes.

O sistema regional árabe de proteção dos direitos humanos está em constituição, entretanto, observa-se em seu endereço na rede mundial de computadores (site oficial) uma gama de discussões no âmbito dos direitos humanos e suas dificuldades no trato com as legislações domésticas dos países membros da Liga dos Estados Árabes, os quais não concluíram uma legislação supranacional para seus membros quanto aos direitos humanos.

Isso está implicado na consideração do poder temporal do governante de cada nação da Liga e seu reporte aos livros sagrados nas prescrições dos documentos internacionais que elaboraram para a tutela dos assuntos relativos aos direitos humanos, a Carta Árabe dos Direitos Humanos e a Declaração do Cairo dos Direitos Humanos.

Esses tratados internacionais islâmicos de direitos humanos corroboram entre si quando manifestamente dispõem no corpo de seus textos que as disposições em contrário devem ser interpretadas com base nas leis corânicas, na palavra e vida do profeta, as quais derivam das revelações contidas no livro sagrado, o que desconsidera totalmente a possibilidade de um Estado desvinculado do poder espiritual, facilitando que ocorram violações dos direitos fundamentais dos povos islâmicos e que esses desmandos fiquem abafados.

A legitimidade para a atipicidade das violações de direitos humanos dos Estados da Liga Árabe é verificada conforme o disposto nos artigos $24^{6}$ e 25 da Declaração do Cairo dos Direitos Humanos, onde afirma que tudo o que está na Declaração é sujeito à Sharia islâmica e segundo o que dispõe o artigo $4^{07}$ da Carta Árabe dos Direitos Humanos, em situações de emergência e ameaça, as quais não foram especificadas no corpo do texto, as obrigações da Carta podem ser derrogadas.

A tutela dos direitos fundamentais dos povos islâmicos pelo sistema regional árabe de proteção dos direitos humanos existe nos tratados internacionais islâmicos estudados, entretanto, inexistem enquanto Comissão de processamento das petições de violações dos direitos humanos e Corte para julgamento desses pedidos, portanto, as tutelas dos direitos fundamentais dos povos das comunidades muçulmanas são insatisfatórias a quem se destinam

\footnotetext{
${ }^{6}$ Artigo 24: Todos os direitos e as liberdades estabelecidos nesta Declaração estão sujeitos à Sharia islâmica. (CAIRO DECLARATION ON HUMAN RIGHTS).

${ }^{7}$ Artigo 4 - 1. Em situações excepcionais de emergência que ameace a vida da nação e a existência do que é oficialmente proclamada, os Estados membros da presente carta podem tomar medidas de derrogação de suas obrigações nos termos da presente carta, na medida do estritamente necessário para as exigências da situação, desde que tais medidas não sejam incompatíveis com as suas outras obrigações no âmbito do direito internacional e não implicar discriminação exclusivamente por motivos de raça, cor , sexo, idioma, religião ou origem social. [...]. (ARAB CHARTER ON HUMAN RIGHTS).
} 
e a própria Liga dos Estados Árabes carece de neutralidade para exigir dos Estados membros tutelas quanto aos direitos humanos.

Ainda, os textos da Declaração do Cairo dos Direitos Humanos e da Carta Árabe dos Direitos Humanos discordam em seu próprio corpo, prescrevendo a proteção dos direitos fundamentais e retirando-a nos artigos seguintes, ora por dirimirem as dúvidas que possam surgir em casos concretos retornando às prescrições da Sharia, ora por declararem direitos e os tornarem suspensos.

Considerando a diversidade cultural, os diferentes anseios dos povos e construções de valores, o princípio da laicidade aplicado às organizações dos Estados, suas instituições e como norte para seus governos, independentemente da cultura dos povos é um caminho a ser discutido pela sociedade internacional neste século XXI, buscando cunhar direitos em âmbito internacional dos direitos humanos afeto a todos, o que propiciará a melhor eficácia no funcionamento dos sistemas de proteção dos direitos humanos.

\section{Referências}

ACHOUR, Yadh Ben. Politique, religion et droit dans le monde arabe. Tunis: Cérès Productions, 1992.

ARAB CHARTER ON HUMAN RIGHTS. Minnesota: Human Rights Library. University of Minnesota, 2012.

ARBEX, José. Islã, um enigma de nossa época. São Paulo: Moderna, 1997.

ARNALDEZ, Roger. La loi musulmane à la lumière des sciences coraniques. Archives de Philosophie du droit - Droit et religion, Tome 36. Paris: Sirey, 1991.

BALTA, Paul. L’Islam. L’État des religions dans le monde. In: Michel Clévenat. Paris: La Découverte/Le Cerf, 1986, p.144-167.

BELTRÃO, J.F.; BRITO FILHO, J. C. M.; GÓMEZ, I; PAJARES, E.; PAREDES, F.; ZÚÑIGA, Y.. Prólogo. Comité Científico. Derechos humanos de los grupos vulnerables. Barcelona: UPF - Universitat Pompeu Fabra, 2015.

BLANES SALA, José. Relações Internacionais e Direitos Humanos. Marília: Cultura Acadêmica, 2011.

BARROSO, Luís Roberto. Temas de Direito Constitucional - Tomo II. Rio de Janeiro: 2. ed. Renovar, 2009.

CAIRO DECLARATION ON HUMAN RIGHTS. Minnesota: Human Rights Library. University of Minnesota, 2012. 
COELHO, Rodrigo Meirelles Gaspar. Proteção internacional dos direitos humanos. Curitiba: Juruá, 2008.

COMPARATO, Fábio Konder. A afirmação histórica dos direito humanos. 7. ed.. São Paulo: Saraiva, 2010.

DEMANT, Peter. O mundo muçulmano. São Paulo: Contexto, 2011.

DONELLY, Jack. The relative universality of human rights. Human rights quarterly, v. 29, n. 2, May 2007, p. 281-306, Published by The Johns Hopkins University Press, 2007.

FEFERBAUM, Marina. Proteção Internacional dos Direitos Humanos - Análise do Sistema Africano. São Paulo: Saraiva, 2012.

HERRERA FLORES, Joaquín Herrera. Teoria Crítica dos Direitos Humanos. Rio de Janeiro: Lumen Juris, 2009.

HOURANI, Albert. Uma história dos povos árabes. São Paulo: Companhia das Letras, 2011.

KAYAOGLU, Turan. It's time to revise the Cairo Declaration on Human Rights in Islam. Brookings Doha Center, April, 2012. Disponível em: <http://www.brookings.edu/research/opinions/2012/04/23-cairo-kayaoglu>. Acesso em 03.mar.2016.

LUGO, Yolanda. Sistema internacional de protección de los derechos de las mujeres. In: Derechos humanos de los grupos vulnerables. Barcelona: UPF - Universitat Pompeu Fabra, 2015, p. 156-184.

MAOMÉ. O Alcorão. Tradução e notas de Mansour Challita. 4. ed. Rio de Janeiro: Best Bolso, 2012.

MATTHES, Rafael Antonietti. O direito humano ao meio ambiente ecologicamente equilibrado no sistema africano e a interpretação da corte africana de direitos humanos. XXIV CONPEDI - UFMG/FUMEC/Dom Hélder Câmara. Belo Horizonte, 2012, p.7-36.

NIETZSCHE, Friedrich Wilhelm. Além do bem e do mal - Prelúdio de uma filosofia do futuro. Coleção O essencial de Nietzsche. Tradução de Antônio Carlos Braga. São Paulo: Editora Escala, 2013.

OLIVEIRA, Adriana F. S. As Convenções Islâmicas sobre direitos humanos e a tutela dos direitos fundamentais das mulheres muçulmanas. São Paulo: LiberArs, 2014.

ONU. Declaração dos Direitos Universais do Homem, 1948. Disponível em: http://portal.mj.gov.br/sedh/ct/legis_intern/ddh_bib_inter_universal.htm. Acesso em 18.dez.2015. 
PAULILO, Maria Ângela Silveira. A pesquisa qualitativa e a história de vida. Serviço Social Revista, 1999, n. 2, v.1, p. 135-148. Disponível em: <http://www.ssrevista.uel.br/c_v2n1_pesquisa.htm>. Acesso em 04.03.2016.

PIOVESAN, Flávia. Direitos Humanos e Justiça Internacional. 2. ed.. São Paulo: Saraiva, 2011.

SAID, Edward W. Cultura e imperialismo. São Paulo: Companhia das Letras, 1995. SILVA, Teresa de Almeida. Islão, Fundamentalismo Islâmico . Pactor. Lisboa, 2011.

THE ARAB LEAGUE AND HUMAN RIGHTS: CHALLENGES AHEAD. Regional Seminar held in Cairo, 2013.

TRINDADE, Antônio Augusto Cançado. Tratado de direito internacional dos direitos humanos. v.1. Porto Alegre: Sérgio Antônio Fabris Editor, 1997. 